\title{
SPECTRUM OF CHEST X-RAY FINDINGS AMONG HUMAN IMMUNODEFICIENCY VIRUS POSITIVE INDIVIDUALS IN A NIGERIAN TERTIARY HOSPITAL
}

\author{
Akinola RA ${ }^{1}$, Balogun $\mathrm{TM}^{2}$, Adeniyi $\mathrm{AA}^{3}$, Onakoya $\mathrm{JAA}^{4}$, Fadeyibi $10^{5}$ \\ 1 Department of Radiology, Lagos State University Teaching Hospital, College of Medicine, Lagos State University, \\ Ikeja, Logos, Nigeria \\ 2 Department of Hematology, Lagos State University Teaching Hospital, Ikeja, Lagos, Nigeria \\ 3 Department of Dentistry, Lagos State University Teaching Hospital, College of Medicine, Ikeja, Lagos, Nigeria \\ 4 Department of Chemical Pathology, Lagos State University Teaching Hospital, College of Medicine, Ikeja, Lagos, \\ Nigeria \\ 5 Department of Surgery, Burns/Plastic Unit, Lagos State University Teaching Hospital, College of Medicine, Ikeja, \\ Lagos, Nigeria
}

\section{ABSTRACT}

Introduction: Human immunodeficiency virus infection damages the immune system making those affected more susceptible to opportunistic infections and malignancies which are common in the chest. This study sought to determine the pattern of chest $\mathrm{X}$-ray lesions and the corresponding CD4 counts of HIV positive patients reporting in the antiretroviral clinic of this teaching hospital for the first time.

Methodology: Consecutive HIV positive patients that attended the antiretroviral clinic of the Lagos State University Teaching Hospital, (LASUTH) from September 2009 to January 2011 were recruited. Their chest $\mathrm{x}$-rays were assessed for the presence of pulmonary lesions and baseline CD 4 counts were done to assess their degree of immunosuppression. Data were analyzed using the Statistical Package for Social Sciences, version 16.0.

Results: There were 211 subjects, 151 females and 60 males with a M:F ratio of 1:2.5 The mean age of participants was $36.5 \pm 11$.9. Mean baseline CD4 count for the subjects was $279 \pm 220.7$ cells/ $\mathrm{mm}^{3}$. Almost two thirds $(64.9 \%)$ cases had normal chest x-rays with their mean CD4 count as $277.65 \pm$ $228.54 \mathrm{cell} / \mathrm{s} / \mathrm{mm}^{3}$. The commonest lesions seen in the lungs include pulmonary infiltrations, $55(26.1 \%)$, cardiomegaly, 24 (11.4\%), pulmonary consolidation, 21 (10\%) and lymphadenopathy, 14 (6.6\%). The commonest radiological diagnosis made were Atypical pneumonitis, 39 (18.5\%), pulmonary TB, 13 (6.2\%), pneumonia $13(6.2 \%)$ and cardiomegaly $13(6.2 \%)$ respectively.Patients with chest findings had lower mean CD4 counts, 239 cells $/ \mathrm{mm}^{3}$ when compared to those without, 244cells $/ \mathrm{mm}^{3}$.

Conclusion: Pulmonary infiltration was the commonest lesion, while the commonest diagnosis was atypical pneumonitis. Patients with chest $\mathrm{x}$-ray lesions were found to have lower CD4 counts with probable worse destruction of their immune system.

Key words: AIDS, CD 4 Count, Chest X-ray findings, HIV.

\section{INTRODUCTION}

Infections by the Human immunodeficiency virus (HIV) and the attendant Acquired immune

\section{Correspondence:}

Dr. Rachael Adeyanju Akinola

Department of Radiology, Lagos State University Teaching

Hospital, College of Medicine, Lagos State University,

Ikeja, Logos, Nigeria. deficiency syndrome (AIDS) have attracted the attention of various researchers globally because of the resultant high morbidity and mortality. 1,2,3,4 AIDS has resulted in a global epidemic affecting an estimated 33.4-39.5 million people with about 2 million dying from AIDS related disease each year. ${ }^{5,6,7}$ Sub-Saharan Africa has the largest number of HIV infected subjects worldwide and Nigeria still has the $2^{\text {nd }}$ largest number of people 
living with HIVIAIDS (PLWH) in sub Saharan Africa and the highest in the WestAfrican sub region. ${ }^{3,8}$ The virus progressively damages the immune system making the body more susceptible to infections. The CD4 count is one of the surrogate markers for evaluating the degree of immunosuppression and HIV disease progression. ${ }^{9}$ The respiratory tract is often affected and patients may present with pulmonary tuberculosis (PTB) and pneumonia. Pulmonary complications are often the initial clinical manifestation of HIV infection while pneumonia and respiratory failure are the most common causes of death in the late stages of HIV infection. ${ }^{2}$

It is a well-established fact that infections and neoplasm coexist in the chest of PLWH. ${ }^{10}$ HIV infection has also contributed significantly to the resurgence of TB, especially in Sub-Saharan Africa ${ }^{11,12}$ and TB is the commonest opportunistic infection and an important cause of death in PLWH in developing countries. It accounts for $40 \%$ of all manifestations seen in HIV patients, ${ }^{13,14}$ and also accounts for $40 \%$ of AIDS death in Africa and Asia and one third of AIDS death worldwide. ${ }^{9}$

Pulmonary complication of HIV infection, even in the current era of potent antiretroviral therapy remains an important issue to contend with because of diagnostic challenges in our environment. Radiological imaging is a very important tool in assessing and following up PLWH and the World Health Organization (WHO) recommends the use of chest $x$-rays (CXR) as part of the TB screening in PLWH. ${ }^{11,14,15}$ This is because annual chest $x$-ray may be an effective, inexpensive and readily available tool especially in developing countries where access to advanced imaging is limited and which when available, is often unaffordable. The sensitivity and specificity for CXR in detecting pulmonary complications in PLWH was $98 \%$ and $93 \%$ respectively. ${ }^{16}$

This study therefore sought to determine the pattern of chest radiographic lesions and the corresponding CD4 counts of HIV positive patients reporting in the antiretroviral clinic of this tertiary institution for the first time. It is envisaged that the outcome of this study will augment the use of chest $x$-ray in the management of Nigerian HIV patients where there is limited availability and affordability of the newer imaging facilities such as the CT scan. This may provide information that will help improve the management of PLWH by health care providers and possibly impact the treatment outcomes of the target population.

\section{METHODOLOGY}

A hospital based prospective, descriptive study was conducted in a 700 bedded teaching hospital in Lagos, South-Western Nigeria. Lagos has a population of approximately 17 million $^{17}$ and LASUTH is the largest State referral center within this environ.

The study recruited 332 consecutive patients who had been confirmed HIV positive and required baseline chest $\mathrm{x}$-ray to confirm the presence or absence of respiratory complications. Information on previous medical history was retrieved from their case notes. The study was conducted from September 2009 to January 2011 following ethical approval by the Research and Ethics committee of the hospital.

Standard postero-anterior (PA) chest X-ray images were taken in full inspiration, using a static $X$-ray machine, Proteus XR/a Revolution XR/d and Definium 8000 X-ray Systems (General Electric, $\mathrm{GE}$ ) and assessed by the Radiologist using a well illuminated viewing box.

The presence of alveolar and interstitial pulmonary infiltration, lobar or pneumonic consolidation, and features of pulmonary TB, enlarged lymph nodes, pleural effusion, pleural thickening, fibrosis and cavitation with their distribution were documented.

As part of their baseline investigations in the HIV clinic, blood samples were collected and analyzed for initial CD 4 counts, using the Cyflow SL (ParterGmb, Germany). CD 4 counts were only available in 211 out of the 332 study subjects seen and therefore, only these were used in this study.

\section{Definition of cases}

Atypical Pneumonitis was defined as widespread pulmonary nodule of less than $1 \mathrm{~cm}$ in diameter which could be uni or bilateral. Pneumonia was 
defined as affectation of one or more segments or lobes of the lung. ${ }^{4}$

Typical pulmonary TB on chest $x$-ray was defined as upper lobe fibrosis, bilateral infiltrates, consolidation and cavitation, while atypical cases were diagnosed when there is less cavitation, enlarged mediastinal lymph nodes, lower lobe and diffuse interstitial infiltrates. ${ }^{9,13,18,19}$ Miliary TB was diagnosed when bilateral multiple discrete widespread lung nodules, $1-2 \mathrm{~mm}$ in diameter were seen. ${ }^{20}$

Fibrosis was seen as discrete linear opacities. Reticulonodular lesions were defined as nodular lesions with interspersed streaky opacities giving a mesh work appearance. Plate atelectasis was seen as short horizontal linear opacities, mostly in the lung bases. Immunological status was assessed by using CD 4 counts and patients with counts $<500$ cells $/ \mathrm{mm}^{3}$ were classified as having immunosuppression. ${ }^{13}$

\section{Data Analysis and Statistical management}

Findings were entered into an excel spread sheet and subsequently into a SPSS data sheet and analysis was done using the SPSS version 16.0, Chicago Illinois. Frequency tables were generated for all variables and measures of central tendency computed for numerical variables. Chi square test and analysis of variance were used to compare means. The level of significance was set at $p \leq 0.05$ and $95 \%$ confidence interval was used throughout.

\section{RESULTS}

The age range of the study subjects was 3-90 years with a mean of $36.5 \pm 11.9$. The male: female ratio was 1:2.5. Radiological diagnosis revealed that $137(64.9 \%)$ had normal chest while $74(35.1 \%)$ were abnormal. The CD4 counts of the study subjects ranged from 6-1246 cells $/ \mathrm{mm}^{3}$, with a mean of $279 \pm 220.7 \mathrm{cell} / \mathrm{s} / \mathrm{mm}^{3}$.

ChestX-ray findings: The commonestlesions seen in the lungs were, alveolar or interstitial pulmonary infiltrations, (figure 1), 55 (26.1\%), cardiomegaly, $24(11.4 \%)$, pulmonary consolidation, (figure 2), $21(10 \%)$ and enlarged lymph nodes, (figure 3), 14 (6.6\%).

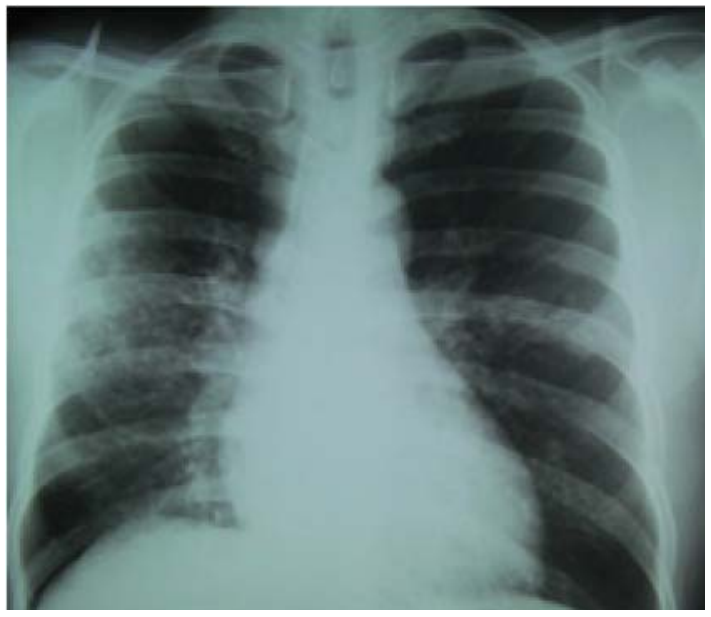

Figure 1. Postero-Anterior (PA) Chest X-Ray showing bilateral pulmonary infiltrates in the mid and lower lung zones.

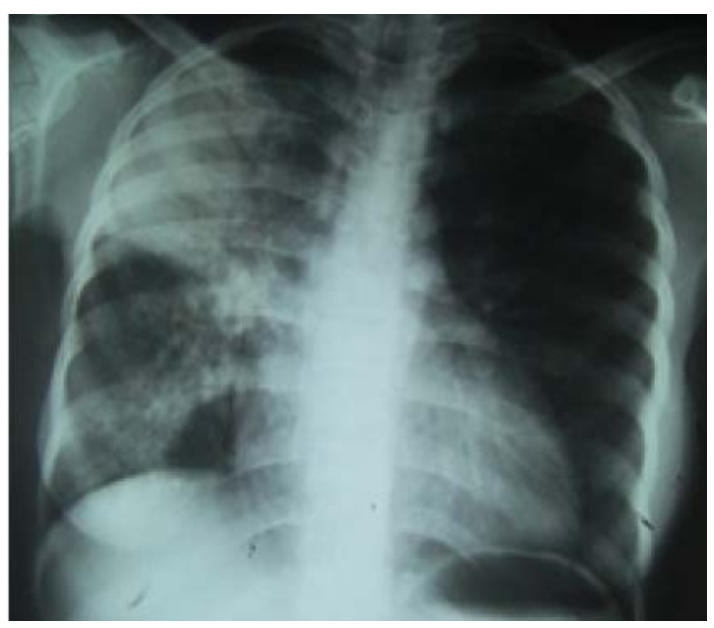

Figure 2. PA Chest $X$-ray showing an area of homogenous lung consolidation in the right upper lobe, right hilar adenopathy and patchy pulmonary infiltrates in the right lower lobe.

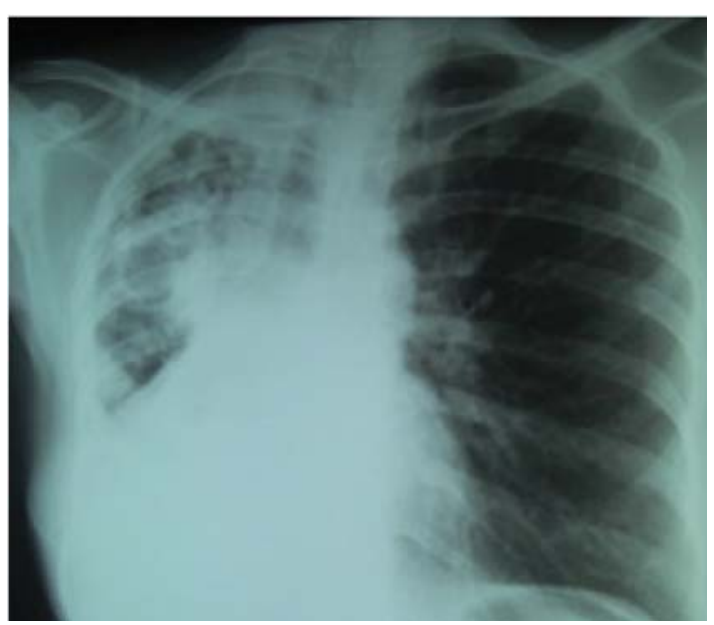

Figure 3. PA Chest X-ray showing shift of the mediastinum and trachea to the right, patchy pulmonary infiltrates in the right upper lobe and right hilar adenopathy. 
The right costophrenic angle and the right diaphragm is obscured which may also suggest some pleural effusion.

The lesions were seen mainly in the lower lobe, $18(24.3 \%)$, while the upper and mid lung zones were equally affected $3(4.1 \%)$. The alveolar or interstitial infiltrates and lobar or pulmonary consolidation were bilateral in $33(44.6 \%)$ and widespread in $19(25.6 \%)$. When unilateral, they occurred more in the right lung, (tables $1 \mathrm{a}$ and $1 \mathrm{~b}$ ).

\begin{tabular}{|l|c|c|}
\hline \multicolumn{3}{|l|}{ Table 1a. Abnormal Chest $x$-ray findings } \\
\hline \multicolumn{1}{|l|}{ LESIONS } & FREQUENCY & $\%$ \\
\hline PULMONARY INFILTERATES & 55 & 26.1 \\
\hline $\begin{array}{l}\text { PULMONARY } \\
\text { CONSOLIDATION }\end{array}$ & 21 & 10.0 \\
\hline $\begin{array}{l}\text { RETICULONODULAR } \\
\text { SHADOWS }\end{array}$ & 2 & 0.9 \\
\hline CAVITIES & 2 & 0.9 \\
\hline FIBROSIS & 4 & 1.9 \\
\hline ENLARGED LYMPH NODES & 14 & 6.6 \\
\hline PLEURAL EFFUSION & 4 & 1.9 \\
\hline PLATE ATELECTESIS & 4 & 1.9 \\
\hline CARDIOMEGALY & 24 & 11.4 \\
\hline
\end{tabular}

${ }^{* *} A$ combination of these lesions can occur in one participant

\begin{tabular}{|l|l|l|}
\hline \multicolumn{3}{|l|}{ Table 1 b. Distribution of lesion in the abnormal Lungs } \\
\hline DISTRIBUTION OF LESION & FREQUENCY & $\%$ \\
\hline UPPER LOBE & 3 & 4.1 \\
\hline LOWER LOBE & 18 & 24.3 \\
\hline MID LUNG ZONE & 3 & 4.1 \\
\hline WIDESPREAD & 19 & 25.6 \\
\hline BILATERAL & 33 & 44.6 \\
\hline UNILATERAL & 2 & 2.7 \\
\hline RIGHT LUNG ONLY & 5 & 6.8 \\
\hline LEFT LUNG ONLY & 2 & 2.7 \\
\hline
\end{tabular}

${ }^{* *}$ More than one region of the lungs can be affected in an individual

Of those that had enlarged lymph nodes, only one was mediastinal, with most, $6(2.8 \%)$ of them in the right hilum, $2(0.9 \%)$ were bilateral and 3 $(1.5 \%)$ were calcified. The least frequent findings were pleural effusion, cavitation, plate atelectasis, fibrosis and emphysema, (table 1a).

Radiological Diagnosis showed that almost two thirds of the study subjects had normal chest $x$-rays. A radiological diagnosis of atypical pneumonitis in $39(18.5 \%)$, (figure 4$)$, suspicious of pulmonary tuberculosis, (figure 5) was made in $13(6.2 \%)$, cardiomegaly and Lobar pneumonia in $6.2 \%$ each, (table 2).

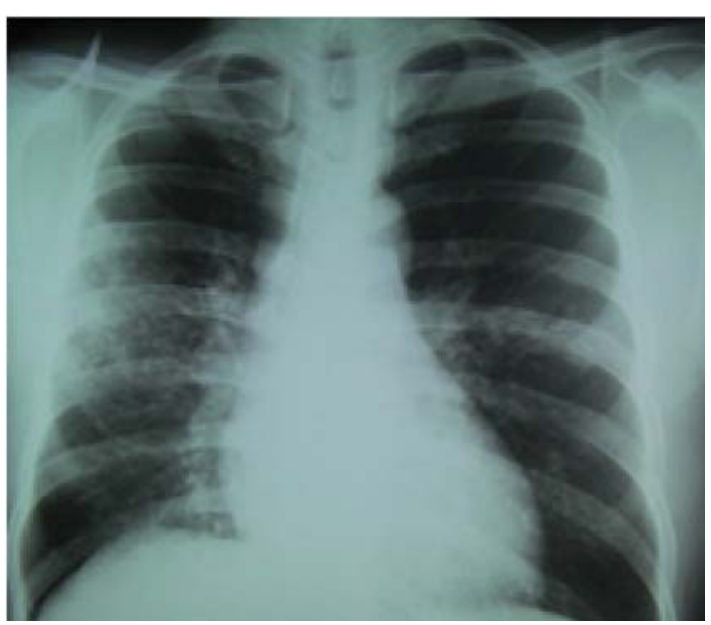

Figure 4. PA Chest $X$-ray showing widespread, bilateral, ill defined, pulmonary infiltrates suggesting atypical pneumonitis with coexisting bilateral pleural effusion. Note the ground glass appearance in the right lower lobe.

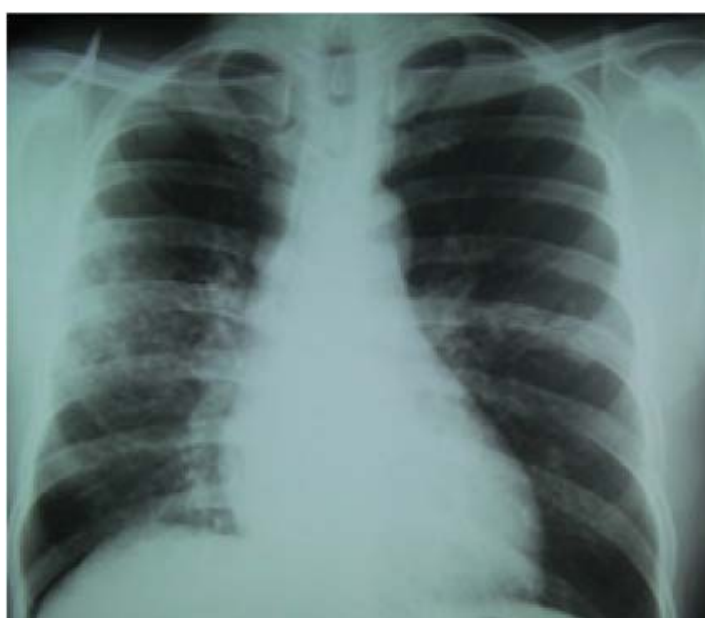

Figure 5. PA Chest X-ray showing bilateral widespread patchy pulmonary infiltrates interspersed with streaky fibrotic shadows and suggestion of a perihilar cavity. These features are highly suggestive of pulmonary tuberculosis. 
Table 2. Radiological diagnosis versus Mean CD 4 Count

\begin{tabular}{|c|c|c|c|c|c|}
\hline \multirow[b]{2}{*}{ RADIOLOGICL DIAGNOSIS } & \multirow[b]{2}{*}{ FREQUENCY } & \multirow[b]{2}{*}{$\%$} & \multicolumn{2}{|c|}{$\begin{array}{c}\text { MEAN CD } \\
4 \text { cOUNT cells } / \mathrm{mm}^{3}\end{array}$} & \multirow[b]{2}{*}{ p VALUE } \\
\hline & & & $\begin{array}{c}\text { Subjects who had } \\
\text { positive radiological } \\
\text { diagnosis }\end{array}$ & $\begin{array}{c}\text { Subjects who had } \\
\text { negative radiological } \\
\text { diagnosis }\end{array}$ & \\
\hline TB & 13 & 6.2 & 217.00 & 283.09 & 0.297 \\
\hline PNEUMONIA & 13 & 6.2 & 234.00 & 281.97 & 0.449 \\
\hline ATYPICAL PNEUMONITIS & 39 & 18.5 & 281.44 & 278.47 & 0.940 \\
\hline CARDIOMEGALY & 13 & 6.2 & 379.38 & 272.42 & 0.091 \\
\hline EMPHYSEMA & 1 & 0.5 & 490.00 & 278.01 & 0.339 \\
\hline PLATE ATELECTESIS & 2 & 0.9 & 127.50 & 280.46 & 0.330 \\
\hline $\begin{array}{l}\text { CONGESTIVE CARDIAC } \\
\text { FAILURE }\end{array}$ & 1 & 0.5 & 189.00 & 279.44 & 0.684 \\
\hline
\end{tabular}

Generally, the mean CD 4 counts were relatively lower in patients with pulmonary manifestations. The mean CD 4 counts in subjects that had cardiomegaly, reticulonodular shadows, and emphysema was the highest while those with unilateral lesions had the least CD4 count, (table 3).

\begin{tabular}{|c|c|c|c|}
\hline $\begin{array}{l}\text { Table 3. Chest } x-r \\
\text { mean CD } 4 \text { counts }\end{array}$ & findings ar & d their dist & tion versus \\
\hline $\begin{array}{c}\text { CHEST X-RAY } \\
\text { FINDING }\end{array}$ & $\begin{array}{r}\text { MEAN CD } \\
\text { cells }\end{array}$ & $\begin{array}{l}4 \text { COUNT } \\
/ \mathrm{mm}^{3}\end{array}$ & \\
\hline & $\begin{array}{l}\text { Subjects } \\
\text { who had } \\
\text { the stated } \\
\text { lesions }\end{array}$ & $\begin{array}{l}\text { Subjects } \\
\text { who did } \\
\text { not have } \\
\text { the stated } \\
\text { lesions }\end{array}$ & P VALUE \\
\hline LESIONS SEEN & & & \\
\hline Pulmonary Infiltrates & 258.55 & 286.23 & 0.425 \\
\hline Lobar Pneumonia & 251.05 & 282.11 & 0.542 \\
\hline Plate Atelectesis & 236.50 & 279.84 & 0.698 \\
\hline Pleural Effusion & 270.00 & 281.62 & 0.911 \\
\hline $\begin{array}{l}\text { Reticulonodular } \\
\text { shadows }\end{array}$ & 305.70 & 278.50 & 0.807 \\
\hline Fibrosis & 190.00 & 278.50 & 0.190 \\
\hline Emphysema & 490.00 & 278.01 & 0.680 \\
\hline Cavity & 233.00 & 279.45 & 0.768 \\
\hline Enlarged Lymph nodes & 278.00 & 279.09 & 0.986 \\
\hline Cardiomegaly & 318.75 & 274.60 & 0.620 \\
\hline DISTRIBUTION OF & LESIONS & & \\
\hline Upper Lung zone & 227.33 & 279.76 & 0.684 \\
\hline Lower Lung zone & 246.89 & 280.97 & 0.539 \\
\hline Middle Lung zone & 291.67 & 278.83 & 0.921 \\
\hline Widespread & 252.42 & 281.65 & 0.583 \\
\hline Right Lung & 171.40 & 281.63 & 0.271 \\
\hline Left Lung & 215.00 & 279.63 & 0.681 \\
\hline Unilateral & 81.00 & 280.91 & 0.203 \\
\hline Bilateral & 257.73 & 282.96 & 0.548 \\
\hline
\end{tabular}

The study therefore showed that the commonest chest imaging findings in HIV antiretroviral naïve patients were atypical pneumonitis, tuberculosis, pneumonia and cardiomegaly and that lesions of pulmonary TB, atypical pneumonitis and pneumonia were overlapping and cannot be readily differentiated from each other which could result in delayed diagnosis treatment.

\section{DISCUSSION}

More females than the males were infected with the HIV in this study. This is similar to the findings in Tanzania by Nwogi et al. ${ }^{13}$ Females are more vulnerable to HIV infection than males because of their biological make up, and socio-cultural factors such as polygamy and prostitution. Contrarily however, other studies in Nigeria and Cuba found that more males were infected in their studies. ${ }^{9,21}$

The fact that more of the chest $x$-rays in this study were normal does not however rule out chest pathologies in these patients. Hollermann et $\mathrm{al}^{10}$ and $\mathrm{Yoo}$ et $\mathrm{a}^{22}$ had earlier reported in their studies that the chest $x$-ray may be normal in HIV positive patients with Pneumocystitis carina pneumonia (PCP) and TB. The absence of radiographic findings in many of the cases in the present study may also represent the early stages of the disease.

The conventional chest $x$-ray (CXR) is usually the first line and often only imaging investigation for HIV patients suspected for respiratory complications. ${ }^{4}$ Despite the variety of differential diagnoses, overlapping features, atypical manifestations and multifactorial disease, the CXR is accurate for diagnosing common chest complications, with reported accuracies of $64 \%, 75 \%$ and $84 \%$ 
for diagnosing bacterial pneumonia, PCP and Microbacterium Tuberculosis (MTB), respectively, in a blinded trial. ${ }^{4}$

The present study agrees with Allen et al ${ }^{4}$ who reported that limitations reflecting overlapping appearances, atypical manifestations and coexisting disease contribute to a relative lack of specificity of imaging. However, certain basic radiographic patterns can be recognized, which should raise the suspicion of certain underlying disease process. ${ }^{4}$

A report by Allen et al in clinical radiology identified bacterial pneumonia as the most common cause of focal consolidation in AIDS. ${ }^{4}$

In the present study, about one third (35.1\%) of the chest radiographs showed abnormalities which was much less than was found by Janzen et al. ${ }^{16}$ This may be because their patients, though immunocompromised were not HIV positive. The chest lesions found in this study include pulmonary infiltrates, more at the lower lobes and bilateral, with enlarged hilar lymph nodes as the predominant features. There were few cavitations. Pulmonary infiltrates was the most common lesion in the present study similar to the study by Janzen et al, while the commonest radiological diagnosis by Janzen et al was TB which correlates well with findings in some African and some centers in some Western countries. ${ }^{16}$ This was however contrary to what was found in this study where TB occurred only in $6.2 \%$ cases. The difference might be because Janzen et al's study was amongst immunocompromized subjects who were HIV negative. ${ }^{16}$

The abnormal chest radiographs in this study, predominantly atypical pneumonia was contrary to findings by Boiselle et $\mathrm{al}^{23}$ which reported that bacterial pneumonia was the most common diagnosis. Unlike the study done in Ethiopia in $2011^{2}$ where pleural effusions are said to be a common finding in HIV patients, it was one of the least common finding in this study. This study was however contrary to Assefa et al's ${ }^{19}$ study which claimed that Pulmonary tuberculosis (TB), bacterial pneumonia (BP) and Pneumocystis pneumonia (PCP), account for the major causes of pneumonia-like syndromes seen in HIV-AIDS patients.

Our findings however differed greatly from the study done in Calabar, South East Nigeria; by Peters et al ${ }^{24}$ where it was found that lung consolidation was the commonest respiratory sign as seen in $44 \%$ of the cases. Hilar lymphadenopathy was seen in $(35 \%)$, but it was much less, $6.6 \%$ in the present study. However, pleural effusion (32\%) and lung fibrosis $(21 \%)$ in their study were amongst the least common findings in this study.

More people in the developed world are also contracting TB because their immune systems are compromised by AIDS, immunosuppressive drugs and substance abuse. ${ }^{12}$ Between 30-40\% of AIDS patients in the world have been found to have coexisting TB. ${ }^{12}$ Microbacterium TB (MTB) is the most common pulmonary complication of HIV worldwide. ${ }^{4,11,12,13}$

The radiographic appearance of TB in AIDS differs from that in immune competent hosts, with more diffuse and lower zone disease, miliary disease and adenopathy as well as an increased incidence of a normal CXR. ${ }^{4}$ Nearly half $(41.2 \%)$ of our study subjects were suspected to have TB on presentation. This was much less than the findings by Reyes et al ${ }^{21}$ where pulmonary tuberculosis was the form of presentation in $79.2 \%$ of patients. The chest radiographic findings suggesting TB include characteristic upper lobe infiltrates, cavitory lesions with hilar and perihilar opacities. ${ }^{11}$ In the study by Hollermann et $a^{10}{ }^{10}$, atypical or primary pattern of TB was common in patients with CD4 less than $200 \mathrm{cell} / \mathrm{mm}^{3}$, while typical or post primary pattern was common in those with CD4 greater than 200 cell $/ \mathrm{mm}^{3}(p=0.02){ }^{9}$ The same observations were also made among African and American patients in whom there was significant association between low CD4 count and atypical or primary pattern of tuberculosis. ${ }^{9}$ The lower the CD4 count the more the tendency for the chest radiograph findings to be different or atypical. ${ }^{19,25}$

The characteristics of the pulmonary infiltrates and few cavitation that were found in this study is contrary to the findings of much cavitation by 
Nwonwueu ${ }^{11}$ and Desalu et al in the south-eastern part of Nigeria. ${ }^{9}$

At CD4 levels above 400, patients are at risk of infection from relatively virulent organisms, such as bacteria and TB. Lung cancer may also occur at this stage. Between counts of 200 and 400 , patients may suffer from recurrent infection as well as lymphoma. Opportunistic infections and Kaposi sarcoma (KS) are rare at CD4 levels $>200$ and indeed most cases of PCP occur at CD4 counts below 100, along with Mycobacterium avium complex (MAC), fungal infections and Cytomegalovirus (CMV). ${ }^{4}$ Nyamande et al ${ }^{3}$ claim that the lower the CD4 count, the greater the likelihood of both opportunistic and nonopportunistic pulmonary infections. This was corroborated by the present study.

Patients in this study with mean CD4 count greater than $200 \mathrm{cells} / \mathrm{mm}^{3}$ had hilar lymphadenopathies. The only patient with mediastinal lymphadenopathy had a CD4 count that was much less than 200cells/ $\mathrm{mm}^{3}\left(30 \mathrm{cell} / \mathrm{s} / \mathrm{mm}^{3}\right)$ similar to the claims by Desalu et $\mathrm{al}^{9}$ and other studies. The few subjects who had cavities on the chest radiographs in the present study were more immunosuppressed than those who did not have, contrary to findings from previous studies?.

Though the level of immunosuppression were shown to be clinically related to the radiographic manifestation, the CD4 count of the study subjects had no statistically significant correlation with the radiological findings in this study $(p>0.05)$ This is in agreement with results in the study by Desalu et al. ${ }^{9}$

Opportunistic lung infections are said to be commoner at CD4 count levels below 200 cells/ $\mathrm{mm}^{3}$ and this may be responsible for the respiratory findings. ${ }^{19}$ However in the present study the mean CD 4 count was $279 \pm 220.7$ cells $/ \mathrm{mm}^{3}$. This might explain why the diagnosis of TB was much less compared to previous studies.

The radiological findings of cardiomegaly in this study, is similar to the findings in Tanzania where $72 \%$ of the study subjects had cardiomegaly from pericardial effusion. ${ }^{26}$ Pericardial effusion is strongly associated with and is an early manifestation of
HIV infection in Tanzania. ${ }^{26}$ Janda et al also found cardiomegaly and pulmonary arterial enlargement as predominant chest $\mathrm{X}$-ray findings in their study. ${ }^{27}$

With longer survival, cardiovascular complications are becoming manifest in HIV patients and they include cardiomyopathy and pulmonary arterial hypertension. ${ }^{4}$ The cause of cardiomegaly in this study could not however be ascertained because the past medical history was not fully known as information was retrieved from the case notes.

Adenopathy is also most commonly due to infection. ${ }^{4}$ TB is by far the most common cause, accounting for about $85 \%$ of the cases.

The majority of pleural effusions in AIDS are small, occurring with equal incidence in both infection and malignancy. ${ }^{4}$ Pleural effusions were said to be less frequent, usually unilateral and occupying less than one-third of the hemi-thorax ${ }^{25}$, similar to what was observed in our study. There is a higher incidence of pulmonary emphysema among HIVpositive smokers. ${ }^{4}$ This may explain why it was one of the least common finding in this study.

\section{CONCLUSION}

The commonest diagnosis made in this study was atypical pneumonitis, pulmonary tuberculosis, pneumonia and cardiomegaly. Patients with chest $X$-ray lesions were found to have lower CD4 counts with probable worse destruction of their immune system. The difference in the mean CD4 count of those with and those without chest lesions were however not statistically significant ( $p>0.05)$.

\section{REFERENCES}

1. Sansone R, Carobbi S, Alloro G, Strigini P. AIDS in Africa. Ann lg 1989;1:1057-66.

2. Pulmonary Manifestations of HIV Infection (http:/l d3jonline.tripod.com/20-Pulmonary_II/Pulmonary_ Manifestations_of_HIV_Infection.htm)

3. Nyamande K, Lalloo U G and Vawda F. Comparison of plain chest radiography and high-resolution CT in human immunodeficiency virus infected patients with community-acquired pneumonia: a subSaharan Africa study. Br J Radiol 2007;80:302-6. 
4. Allen $\mathrm{CM}, \mathrm{AL}$-Jahdali $\mathrm{HH}$, Irion $\mathrm{KL}, \mathrm{Al}$ Ghanem $\mathrm{S}$, Gouda A, Khan AN. Imaging lung manifestations of HIVIAIDS. Ann Thorac Med 2010;5:201-16.

5. Rotheram-Borus MJ, Swendeman D, Chovnick G. The Past, Present, and Future of HIV Prevention: Integrating Behavioral, Biomedical, and Structural Intervention Strategies for the next generation of HIV Prevention. Annu Rev Clin Psychol 2009;5:143-67.

6. AIDS. Avert, Averting HIV and AIDS. AVERT.org. 2010. UNAIDS 2009, UNAIDS 2010. "Reports on the global aids epidemic" (http://www.avert.org/ aids.htm)

7. HIV testing results. Mayo Clinic House call. 2008 (www.mayoclinic.com/health/hiv-testing/MY00954)

8. PM News. 3.1 Million people infected with HIV in Nigeria (http://pmnewsnigeria. com/2011/03/25about3.1-million-people-infectedwith-hiv-in-Nigeria-health-minister/)

9. Desalu OO, Olokoba A, Danfulahi M, et al. Impact of immunosuppression on radiographic features of HIV related pulmonary tuberculosis among Nigerians/ Nijeryahalkinda HIV ileiliskilibagisikl iksistemininbaskilanmasininakcigertuberkulozu nunradyolojikbulgularinaetkileri. Tur Toraks Der 2009;10:112-16.

10. Hollerman JJ, Bernstein MA, Beute GH. Thoracic manifestation of AIDS. Am Fam Physician 1987;35:109-18.

11. Nwonwueu, Oyibo PG, Imo AOC, Ndukwe CD, Oblonu CN, Uneke CJ. Radiological features of pulmonary tuberculosis in HIV-positive and HIVnegative adult patients in south-eastern Nigeria. Mera:African journal of respiratory medicine 2008;:20-23.

12. Tuberculosis. Winkipedia, The free encyclopedia (http://en.wikipedia.org/wiki/Tuberculosis)

13. Ngowi BJ, Mfinanga SG, Bruun JN, Morkve 0 . Pulmonary tuberculosis among people living with HIVIAIDS attending care and treatment in rural Northern Tanzania. BMC Public Health 2008;8:341.

14. Holemann's JA, HowlettDC, Ayers AB. Imaging the thoracic manifestations of AIDS. Hosp Med 1998:59:352-58.

15. Shah NS, Anh MH, Thuy TT, et al. Population based chest $\mathrm{X}$ - ray screening for pulmonary tuberculosis in people living with HIVIAIDS, An Giang, Vietnam. Int J Tuberc Lung Dis 2008;12:404-10.
16. Janzen DL, Padley SP, Adler BD, Müller N. Acute pulmonary complications in immune compromised non-AIDS patients: comparison of diagnostic accuracy of CT and chest radiography. Clin Radiol 1993;47:159-65.

17. Official website of the Lagos State Government. Population (http://www.lagosstate.gov.ng/index.ph p?page=subpage \&spid=12\&mnu=null)

18. Hsieh SM, Hung CC, Chen MY, et al. Clinical features of tuberculosis associated with HIV infection in Taiwan. $\mathrm{J}$ Formos Med Assoc 1996;95:923-28.

19. Assefa G, Nigussie Y, Aderaye G, Worku A, Lindquist $L$. Chest $X$-ray evaluation of pneumonialike syndromes in smear negative HIV-positive patients with atypical chest $\mathrm{x}$-ray. Findings in Ethiopian setting. Ethiop Med J. 2011;49:35-42.

20. Klaus-Dieter L, Gorla M, Talavera W. Radiographic findings in HIV - positive patients with sensitive and resistant Tuberculosis. Chest 1994;106:687-89.

21. Reyes CA, Diaz JM, Perez Rodriquez A. Tuberculosis and AIDS: various clinical and epidemiological aspects in 72 Cuban patients. Rev Cubana Med Trop 2004;56:35-41.

22. Yoo SD, Cattamanchi A, Boon SD et al. Clinical significance of normal chest radiographs among HIV seropositive patients with suspected tuberculosis in Uganda. Respirology. DOI:10. 1111/j.1440-1843.2011.01981.x

23. Boiselle PM, Aviram G, Fishman JE. Update on lung disease in AIDS. Semin Roentgenol. 2002;37:54-71.

24. Peters EJ, Essien OE, Immananagha KK, Inah GA, Philip-Ephraim EE, Agbulu RE. CD4 count levels and pattern of respiratory complications in HIV seropositive patients in Calabar, Nigeria. Niger J Physiol Sci. 2007;22:93-97.

25. A.E.Oguntoyinbo, D.A. Nzeh, S. A.Salami and A.S.Babatunde. The Chest Radiographs Of Suspected And Confirmed Hiv/Aids Patients Pattern of Radiological Features in Ilorin (http:// www.unilorin.edu.ng/publications. May 2011)

26. Cegielski JP, Ramaiya K, Lallinger GJ, Mtulia IA, Mbaga IM. Pericardial disease and human immunodeficiency virus in Dar es Salaam, Tanzania. The Lancet 1990;335:209-12.

27. Janda S, Quon BS, Swiston J. HIV and Pulmonary arterial hypertension: A systemic review. HIV medicine 2010;11:620-24. 